\title{
Prediagnostic Serum 25-Hydroxyvitamin D and
} Mortality Among Bladder Cancer Patients in the Janus Serum Bank Cohort

\author{
Helga H Hektoen (D' \\ Randi E Gislefoss' \\ Jo S Stenehjem (1) \\ Hilde Langseth' \\ Karol Axcrona ${ }^{2}$ \\ Alison M Mondul ${ }^{3}$ \\ Trude E Robsahm (D) \\ Bettina K Andreassen' \\ 'Department of Research, Cancer \\ Registry of Norway, Oslo, Norway; \\ ${ }^{2}$ Department of Urology, Akershus \\ University Hospital, Lørenskog, Norway; \\ ${ }^{3}$ Department of Epidemiology, University \\ of Michigan School of Public Health, Ann \\ Arbor, MI, USA
}

Purpose: Circulating 25-hydroxyvitamin D (25(OH)D) is inversely associated with overall cancer mortality and selected cancers, while for urothelial bladder cancer (BC) this relationship is unclear. We aimed to examine the association between $25(\mathrm{OH}) \mathrm{D}$ and $\mathrm{BC}$ mortality.

Materials and Methods: We used prediagnostic serum from $378 \mathrm{BC}$ cases within the population-based Janus Cohort. Cox regression models estimated hazard ratios (HRs), with 95\% confidence intervals (CIs), for the association between $25(\mathrm{OH}) \mathrm{D}$ and $\mathrm{BC}$-specific and all-cause mortality. Restricted cubic splines were assessed to examine non-linear risk associations. Analyses were stratified by tumor invasiveness (non-muscle invasive BC (NMIBC) and muscle invasive BC (MIBC)). Additionally, the association between 25(OH)D and allcause mortality was assessed for 378 cancer-free matched controls.

Results: $25(\mathrm{OH}) \mathrm{D}$ deficiency $(<50 \mathrm{nmol} / \mathrm{L})$ was associated with higher BC-specific mortality (HR 1.87, 95\% CI 1.10-3.20), when compared with insufficient levels (50-74 nmol/L). Stratification by tumor invasiveness revealed that this result was evident for NMIBC only, both with respect to BC-specific mortality (HR 2.84, 95\% CI 1.14-7.12) and all-cause mortality (HR 1.97, 95\% CI 1.06-3.65). No association between 25(OH)D levels and allcause mortality was found in cancer-free controls.

Conclusion: $25(\mathrm{OH}) \mathrm{D}$ deficiency $(<50 \mathrm{nmol} / \mathrm{L})$ prior to a $\mathrm{BC}$ diagnosis was associated with increased risk of BC-specific mortality, when compared to insufficient levels (50-74 nmol/ L). The results were evident among NMIBC patients only, suggesting a more critical role of vitamin $\mathrm{D}$ deficiency in an early stage of the disease.

Keywords: cancer, vitamin D, mortality, cancer death, prospective study

\section{Introduction}

Urothelial bladder cancer (BC) is ranked as the 10th most common cancer worldwide, with approximately 550,000 new cases and 200,000 deaths each year. ${ }^{1}$ The risk of dying from $\mathrm{BC}$ increases with age at diagnosis and stage and grade of the disease. $^{2}$ Certain lifestyle factors have been suggested to influence BC prognosis, including smoking status and obesity., 3

During the past two decades, the essential micronutrient vitamin $\mathrm{D}$ has been widely studied in relation to various health outcomes, including cancer mortality. ${ }^{5-7}$ Vitamin D is a fat-soluble pro-hormone that is synthesized in the skin in response to sunlight but can also be obtained from diet and supplement use. ${ }^{8}$ Two hydroxylation steps are required to reach the biologically active state. First in the liver to form 25-hydroxyvitamin $\mathrm{D}(25(\mathrm{OH}) \mathrm{D})$, the main circulating form and the best indicator
Correspondence: Helga H Hektoen Ullernchausseen 64, Oslo, 0379, Norway Tel +4722928921

Email Helga.helseth.

hektoen@kreftregisteret.no 
of an individual's vitamin D status. Then, to form the active state, 1,25-dihydroxyvitamin-D $\left(1,25(\mathrm{OH})_{2} \mathrm{D}\right)$, which through the endocrine way occurs in the kidney. ${ }^{9}$ The active hormone of vitamin D has many biological functions in addition to its well-established roles in calcium homeostasis and bone health. ${ }^{10}$ In vitro and in vivo experiments have shown that $1,25(\mathrm{OH})_{2} \mathrm{D}$ modulates multiple steps involved in carcinogenesis, including inhibition of cancer cell proliferation, promotion of cell differentiation, and anti-inflammatory and anti-angiogenic effects. ${ }^{11}$ One of the most relevant effects of vitamin D for cancer prognosis is its role in decreasing tumor invasiveness and propensity to metastasize. ${ }^{11}$

Randomized controlled trials have shown that vitamin D supplementation slightly decreases the risk of death from all cancers as well as the risk of fatal cancer, compared to placebo effects. ${ }^{12,13}$ Moreover, meta-analyses of observational studies have reported associations between low serum levels of $25(\mathrm{OH}) \mathrm{D}$ and increased cancer mortality. $^{14-19}$ Some observational studies have also found inverse associations between $25(\mathrm{OH}) \mathrm{D}$ levels and cancer-specific mortality in patients with breast, lung, prostate, and colon cancer, ${ }^{20-22}$ which also may be the situation for $\mathrm{BC}$, but the results are conflicting. ${ }^{6,23-25}$

Although many studies have indicated that insufficient levels of $25(\mathrm{OH}) \mathrm{D}$ increase the risk of cancer mortality, a large degree of heterogeneity has been observed in the meta-analyses published. ${ }^{18,19}$ There are huge variations in the reported range and categorization of $25(\mathrm{OH}) \mathrm{D}$ concentrations, partly due to large variability in laboratory methods, but also because of large personal and environmental variations, including variability over the course of the year. ${ }^{26}$ Studies also vary in size, follow-up time, and adjustment for potential confounding factors. Moreover, most meta-analyses do not discriminate between pre- and post-diagnostic serum samples. $^{22}$ To date, most studies on $25(\mathrm{OH}) \mathrm{D}$ and cancer mortality have been performed on serum collected after the cancer diagnosis, which increases the risk of reverse causality, eg that the development and/ or the consequences of having cancer influences $25(\mathrm{OH}) \mathrm{D}$ levels. $^{27}$

In the present study, we aimed to examine how prediagnostic 25(OH)D levels, collected at least five years before diagnosis, were related to $\mathrm{BC}$-specific or all-cause mortality, when adjusting for tumor invasiveness, smoking, body mass index (BMI), physical activity and education. For comparison, we also performed an additional analysis on the association between $25(\mathrm{OH}) \mathrm{D}$ levels and all-cause mortality in cancer-free controls.

\section{Materials and Methods Janus Serum Bank Cohort}

The Janus Serum Bank Cohort (hereafter Janus Cohort) is a population-based biobank preserved for cancer research containing blood samples and health examination data from 292,851 individuals who participated in one of five large national health surveys conducted in Norway in the period $1972-2004 .^{28}$ For each participant, a non-fasting blood sample was collected, and stored at $-25{ }^{\circ} \mathrm{C}$ in the Janus Serum Bank. All participants filled out a questionnaire, including information on smoking habits and physical activity. As part of the health examination, measurements of blood pressure, height, and weight were performed by trained health personnel. ${ }^{29}$

\section{Study Population}

The present study originates from a matched case-control study nested within the Janus Cohort, consisting of 400 cases and 400 controls. $^{30}$ The study selection is described in Figure 1. The Cancer Registry of Norway (CRN) has registered information on all cancer cases diagnosed in Norway since 1953. CRN retrieves information from several independent sources. Reporting is mandatory and the registry holds high quality and complete data. ${ }^{31} \mathrm{BC}$ cases within the Janus Cohort were identified by linkage to the CRN. We included all first primary $\mathrm{BC}$ cases of the translational cell type (histological verified by morphological codes 8120 , 8130 and 8131, International Classification of Disease of Oncology, 3rd revision) without a previous cancer diagnosis (except cutaneous basal cell carcinoma). Information on tumor invasiveness was based on pathological histology reports. $\mathrm{BC}$ cases were categorized as non-muscle invasive bladder cancer (NMIBC), including high-graded papillary non-invasive tumors (Ta), carcinoma in situ (Tis) and tumors invading lamina propria (T1), and muscle invasive bladder cancer (MIBC), including tumors invading muscularis propria and further (T-stage T2-T4). To reduce the possibility for reverse causality, $\mathrm{BC}$ cases had to be diagnosed at least 5 years after blood draw (inclusion). The main cause of death was obtained from the national Cause of Death Registry.

The primary outcomes of the present study were risk of BC-specific death and overall death, which is also referred to as $\mathrm{BC}$-specific mortality and all-cause mortality throughout the paper. The main analyses were performed 


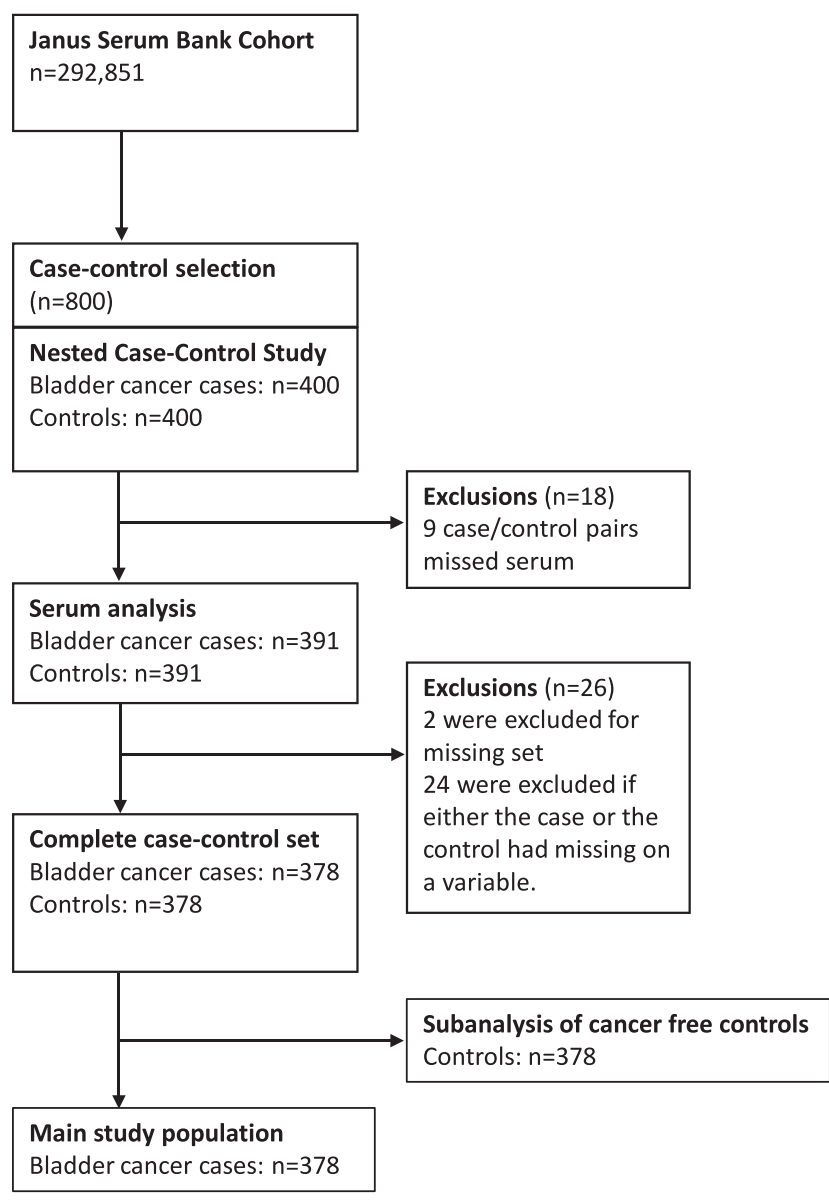

Figure I Overview of study the population.

on the $\mathrm{BC}$ cases. For comparison, when studying all-cause mortality, a sub-analysis was performed on cancer-free controls. One control was matched to each case on sex, year of birth ( \pm 1 year), date of blood draw $( \pm 2$ years), season of blood draw within the following 3-month intervals within the same calendar year (December-February, March-May, June-August, September-November) and county of blood draw. The controls were required to be resident in Norway, alive and without a cancer diagnosis before the index date (date of $\mathrm{BC}$ diagnosis of the associated case).

The individuals were followed from the index date until BC-specific death (cases) or death of all causes (cases and controls), emigration or end of follow-up, whichever occurred first.

\section{$25(\mathrm{OH}) \mathrm{D}$}

25(OH)D concentrations in serum were measured by a liquid chromatography/tandem mass spectrometry method. The National Hormone Laboratory (Oslo
University Hospital), participants of the vitamin D External Quality Assessment Scheme, performed the analysis. The serum samples were distributed across 25 batches, including cases and controls, whereof each batch included a blinded quality control sample. The inter-assay coefficient of variation $(\mathrm{CV})$ was $11.1 \%$ at $60.1 \mathrm{nmol} / \mathrm{L}$ for 25(OH)D.

In Norway, the 25(OH)D levels vary by season. To account for this, the 25(OH)D concentrations were seasonstandardized by performing a least square fit of a sine function to the measured concentrations of $25(\mathrm{OH}) \mathrm{D}$ versus date of blood draw. A detailed description of this method has previously been published. ${ }^{30}$ Levels of 25 $(\mathrm{OH}) \mathrm{D}$ were categorized based on cut points previously defined by the endocrine society; ${ }^{32}$ deficient $(<50 \mathrm{nmol} / \mathrm{L})$, insufficient (50-74 nmol/L), optimal (75-99 nmol/L) and high optimal $(\geq 100 \mathrm{nmol} / \mathrm{L})$, using $50-74 \mathrm{nmol} / \mathrm{L}$ as the reference category, reflecting the average level in the Norwegian population. ${ }^{33}$

\section{Covariates}

Self-reporting smoking status was categorized as never, former and current smokers. BMI was calculated based on the height and weight measurements and categorized according to the World Health Organization's classification: underweight and normal weight $\left(<25 \mathrm{~kg} / \mathrm{m}^{2}\right)$, overweight $\left(25-29.9 \mathrm{~kg} / \mathrm{m}^{2}\right)$ and obese $\left(\geq 30 \mathrm{~kg} / \mathrm{m}^{2}\right)$. Self-reported physical activity level was categorized as sedentary, moderately active and active. Information on educational level was obtained from Statistics Norway and classified as unknown, compulsory, upper secondary, and college/university.

\section{Statistical Analyses}

Descriptive statistics were used to describe patient characteristics. Means with standard deviation or median with interquartile range were reported for continuous variables, frequencies with percentages otherwise. Cox regression was applied to estimate hazard ratios (HRs) and corresponding 95\% confidence intervals (CIs) for the association between 25(OH)D and BC-related risk of death. Moreover, to explore the underlying shape of the effect of interest, the HR was modelled as a restricted cubic spline with 4 knots dependent on $25(\mathrm{OH}) \mathrm{D}$, using the STATA package rscgen. The knots were, following Harrell, placed at the 5th, 35th, 65th and 95th percentiles. ${ }^{34}$ To compare the fit of the linear vs the spline models, a likelihood ratio test was performed. 
All analyses were adjusted for age at index-date in three categories $(<60,60-70 \geq 70)$, sex, year of blood draw in three categories $(<1975,1975-1984$ and $\geq 1985)$, batch number, and tumor-invasiveness (NMIBC and MIBC) (Model 1). In a second model (Model 2), we additionally adjusted for smoking status, BMI, physical activity and education, categorized as described above. As smoking, BMI and physical activity might be effect modifiers of the association between $25(\mathrm{OH}) \mathrm{D}$ and $\mathrm{BC}$ specific mortality, we tested for interaction and conducted analyses stratified by these variables. Statistical interaction was evaluated using the likelihood ratio test.

The $\mathrm{BC}$ cases were followed in 5.6 years (range: $2.1-$ 10.6 years) from index date (BC diagnosis) and 216 deaths occurred of which 110 were $\mathrm{BC}$-specific deaths. Among cancer-free controls, the median follow-up was 8.3 years (range: 5.1-13.3 years), and 125 deaths occurred.

All statistical analyses were performed using STATA version 15.1 (StataCorp, College Station, TX).

\section{Results}

The observed 5- and 10-year BC-specific survival of the $\mathrm{BC}$ patients was $73 \%$ and $68 \%$, respectively. The observed BC-specific survival is also shown in Supplementary Figure 1A for the whole group and stratified by levels of 25(OH)D in Supplementary Figure 1B. Study characteristics by levels of 25(OH)D among BC cases, are shown in Table 1. Individuals who were deficient in 25(OH)D $(<50 \mathrm{nmol} / \mathrm{L})$ were more likely to be current smokers and to have smoked more pack-years, be less physically active and have lower education, compared with individuals with higher $25(\mathrm{OH}) \mathrm{D}$ concentrations $(\geq 50$ $\mathrm{nmol} / \mathrm{L}$ ).

Deficiency in 25(OH)D in BC cases was associated with higher risk of BC-specific mortality (HR 1.87, 95\% CI 1.10-3.20), but not all-cause mortality (HR 1.36, 95\% CI 0.90-2.07), when compared with individuals having insufficient levels (Table 2). When stratifying by tumor invasiveness, this pattern persisted among NMIBC patients (BC-specific mortality: HR 2.84, 95\% CI 1.147.12) and 25(OH)D deficiency was also associated with elevated all-cause mortality among NMIBC (HR 1.97, 95\% CI 1.06-3.65). In contrast, among MIBC, high optimal levels ( $\geq 100 \mathrm{nmol} / \mathrm{L})$ were associated with higher BCspecific mortality (HR 2.93, 95\% CI 1.15-7.51), when compared to insufficient levels.

In cancer-free controls, no association was found between 25(OH)D levels and all-cause mortality (Table 2).
Figure 2 illustrates the adjusted risk of $\mathrm{BC}$-specific and all-cause mortality (HR) in BC cases (A and B) as well as all-cause mortality in cancer-free controls (C), across all 25(OH)D concentrations (Model 2). The highest HRs were observed at concentrations below $50 \mathrm{nmol} / \mathrm{L}$ when compared to the reference value $(62.5 \mathrm{nmol} / \mathrm{L})$ with respect to BC-specific mortality (A). For 25(OH)D concentration above the reference value, the HR increased until it leveled off at approximately $90 \mathrm{nmol} / \mathrm{L}$. A similar pattern was also observed for all-cause mortality among BC cases (B), while among controls the HR for all-cause mortality was stable over the continuous scale of $25(\mathrm{OH}) \mathrm{D}$ concentrations $(\mathrm{C})$.

We also present $\mathrm{BC}$-specific mortality and all-cause mortality (among BC cases) across all concentrations of 25(OH)D (Model 2), stratified by tumor invasiveness (Figure 3). For NMIBC (A and B), the highest risk was observed at concentrations below $50 \mathrm{nmol} / \mathrm{L}$, compared to the reference value $(62.5 \mathrm{nmol} / \mathrm{L})$. For $25(\mathrm{OH}) \mathrm{D}$ concentrations above the reference value, the HR increased up to $90 \mathrm{nmol} / \mathrm{L}$ and thereafter decreased. For MIBC (C and D), the mortality was rather stable across $25(\mathrm{OH}) \mathrm{D}$ concentrations.

For $\mathrm{BC}$ cases, the spline models, which allow the risk ratio of death (HRs) to vary across $25(\mathrm{OH}) \mathrm{D}$ concentrations showed a better fit than the models assuming a constant HR for the association between 25(OH)D and BC-specific and all-cause mortality. For cancer-free controls, the spline model did not show a better fit than the linear model.

No associations between 25(OH)D levels and BCspecific mortality was observed in analyses stratified by smoking status, BMI and physical activity (Table 3). We did not observe any relevant interactions for any of the studied variables.

\section{Discussion}

In this prospective study, using serum samples collected at least 5 years prior to the $\mathrm{BC}$ diagnosis, we found that $25(\mathrm{OH})$ $\mathrm{D}$ deficiency $(<50 \mathrm{nmol} / \mathrm{L})$ was associated with $\mathrm{BC}$-specific mortality, when compared with insufficient levels (50-74 $\mathrm{nmol} / \mathrm{L}$ ). Stratification by tumor invasiveness revealed that this result was evident for NMIBC cases only, and additionally an association was found for all-cause mortality. In a sub-analysis with cancer-free controls, no association between 25(OH)D levels and all-cause mortality was found.

Meta-analyses investigating the association between 25 $(\mathrm{OH}) \mathrm{D}$ and cancer mortality show that individuals with 25 
Table I. Characteristics of Individuals Developing Bladder Cancer, by 25-Hydroxyvitamin D

\begin{tabular}{|c|c|c|c|c|}
\hline \multirow[t]{2}{*}{ Characteristics } & \multicolumn{4}{|c|}{ 25-Hydroxyvitamin D } \\
\hline & $\begin{array}{l}\text { Deficient } \\
<50 \mathrm{nmol} / \mathrm{L}\end{array}$ & $\begin{array}{l}\text { Insufficient } \\
50-74 \mathrm{nmol} / \mathrm{L}\end{array}$ & $\begin{array}{l}\text { Optimal } \\
75-99 \mathrm{nmol} / \mathrm{L}\end{array}$ & $\begin{array}{l}\text { High Optimal } \\
\geq 100 \mathrm{nmol} / \mathrm{L}\end{array}$ \\
\hline $\begin{array}{l}\text { 25-hydroxyvitamin } \mathrm{D} \\
\text { (nmol/L), median (range) }\end{array}$ & $\begin{array}{l}42.8 \\
(17.3-49.9)\end{array}$ & $\begin{array}{l}62.5 \\
(50.3-74.8)\end{array}$ & $\begin{array}{l}85.7 \\
(75.5-99.9)\end{array}$ & $\begin{array}{l}114.4 \\
(101.0-195.4)\end{array}$ \\
\hline Age at blood draw(mean, SD) & $44.3(5.9)$ & $45.5(8.1)$ & $45.1(7.1)$ & $42(6.9)$ \\
\hline Age at diagnosis(mean, SD) & $67.3(9.1)$ & $67.1(9.7)$ & $68.1(10.0)$ & $65.4(9.3)$ \\
\hline $\begin{array}{l}\text { Tumor invasiveness } \\
\text { Non-muscle invasive } \\
\text { Muscle invasive }\end{array}$ & $\begin{array}{l}36(59) \\
25(4 I)\end{array}$ & $\begin{array}{l}111(61) \\
70(39)\end{array}$ & $\begin{array}{l}68(67) \\
34(33)\end{array}$ & $\begin{array}{l}23(68) \\
11(32)\end{array}$ \\
\hline $\begin{array}{c}\text { Sex, } \mathrm{n}(\%) \\
\text { Male, } \\
\text { Female }\end{array}$ & $\begin{array}{l}51(84) \\
10(16)\end{array}$ & $\begin{array}{l}153(85) \\
28(15)\end{array}$ & $\begin{array}{l}86(84) \\
16(16)\end{array}$ & $\begin{array}{l}30(88) \\
4(12)\end{array}$ \\
\hline $\begin{array}{l}\text { Year of blood draw } \\
\quad<1975 \\
1975-1984 \\
\geq 1985\end{array}$ & $\begin{array}{l}17(23) \\
13(21) \\
31(51)\end{array}$ & $\begin{array}{l}40(22) \\
35(19) \\
106(59)\end{array}$ & $\begin{array}{l}30(29) \\
32(31) \\
40(39)\end{array}$ & $\begin{array}{l}11(32) \\
11(32) \\
12(35)\end{array}$ \\
\hline $\begin{array}{l}\text { Smoking status, n (\%) } \\
\text { Never smoker } \\
\text { Former smoker } \\
\text { Current smokers }\end{array}$ & $\begin{array}{l}8(13) \\
9(15) \\
44(72)\end{array}$ & $\begin{array}{l}38(21) \\
39(22) \\
104(57)\end{array}$ & $\begin{array}{l}20(20) \\
25(25) \\
57(56)\end{array}$ & $\begin{array}{l}8(24) \\
7(21) \\
19(56)\end{array}$ \\
\hline Pack years, mean (SD) & $20.3(11.1)$ & $18.3(9.8)$ & $15.6(8.8)$ & $18.8(7.2)$ \\
\hline BMI (kg/m2), mean (SD) & $25.2(3.8)$ & $24.9(3.0)$ & $24.6(2.9)$ & $24.5(1.9)$ \\
\hline $\begin{array}{l}\text { BMI }(\mathrm{kg} / \mathrm{m} 2), \mathrm{n}(\%) \\
\text { Normal }(\leq 25) \\
\text { Overweight }(25-29) \\
\text { Obese }(\geq 30)\end{array}$ & $\begin{array}{l}31(5 I) \\
24(39) \\
6(10)\end{array}$ & $\begin{array}{l}97(54) \\
73(40) \\
11(6)\end{array}$ & $\begin{array}{l}60(59) \\
37(36) \\
4(5)\end{array}$ & $\begin{array}{l}20(59) \\
14(4 \mid) \\
0(0)\end{array}$ \\
\hline $\begin{array}{l}\text { Physical activity, n (\%) } \\
\text { Sedentary } \\
\text { Moderately active } \\
\text { Active }\end{array}$ & $\begin{array}{l}21(34) \\
33(54) \\
7(11)\end{array}$ & $\begin{array}{l}36(20) \\
108(60) \\
37(20)\end{array}$ & $\begin{array}{l}17(17) \\
58(57) \\
27(26)\end{array}$ & $\begin{array}{l}4(12) \\
18(53) \\
12(35)\end{array}$ \\
\hline $\begin{array}{l}\text { Education, } \mathrm{n}(\%) \\
\text { Compulsory } \\
\text { Upper secondary } \\
\text { College/University }\end{array}$ & $\begin{array}{l}28(46) \\
26(43) \\
7(12)\end{array}$ & $\begin{array}{l}63(35) \\
93(51) \\
25(14)\end{array}$ & $\begin{array}{l}36(35) \\
48(47) \\
18(18)\end{array}$ & $\begin{array}{l}10(29) \\
19(56) \\
5(15)\end{array}$ \\
\hline
\end{tabular}

Abbreviations: SD, standard deviation; BMI, body mass index.

$(\mathrm{OH}) \mathrm{D}$ concentrations in the lower range are at increased risk of cancer-specific mortality. ${ }^{18,19}$ However, a large proportion of these studies are based on post-diagnostic serum samples, and it cannot be ruled out that the cancer disease or its consequences (including improved health awareness and illness that consequently can result in changed sun exposure and diet) have influenced the $25(\mathrm{OH}) \mathrm{D}$ levels to some degree. ${ }^{22}$ To reduce this bias, our study was based on prediagnostic 25(OH)D levels, taken at least 5 years prior to a cancer diagnosis.

Two previous studies have shown an inverse relationship between sun exposure and BC-specific mortality, suggesting a beneficial role of vitamin $\mathrm{D}$ in the development of BC..$^{35,36}$ To our knowledge, only one prospective study, examining the association between serum 25(OH)D and $\mathrm{BC}$-specific mortality has been published. ${ }^{23}$ In 
Table 2. Hazard Ratio (HR) and 95\% Confidence Interval (Cl) of Bladder Cancer (BC)-Specific and All-Cause Mortality Among BC Cases, and All-Cause Mortality Among Cancer-Free Controls, by Levels of Season-Adjusted 25-Hydroxyvitamin D

\begin{tabular}{|c|c|c|c|c|}
\hline & \multicolumn{4}{|c|}{ 25-Hydroxyvitamin D } \\
\hline & Deficient & Insufficient & Optimal & High Optimal \\
\hline & $<50 \mathrm{nmol} / \mathrm{L}$ & $50-74 \mathrm{nmol} / \mathrm{L}$ & 75-99 nmol/L & $\geq 100 \mathrm{nmol} / \mathrm{L}$ \\
\hline & HR (95\% Cl) & HR (95\% Cl) & HR (95\% Cl) & HR (95\% Cl) \\
\hline \multicolumn{5}{|l|}{ Bladder cancer (BC) cases } \\
\hline \multicolumn{5}{|l|}{$B C$-specific mortality } \\
\hline$B C(n)$ & 61 & 181 & 102 & 34 \\
\hline Model I & $1.67(0.99-2.82)$ & 1.00 & $1.23(0.76-2.00)$ & $1.76(0.86-3.60)$ \\
\hline Model 2 & $1.87(1.10-3.20)$ & 1.00 & $1.35(0.82-2.21)$ & $1.92(0.93-4.00)$ \\
\hline Non-Muscle Invasive BC (n) & 36 & 111 & 68 & 23 \\
\hline Model $2^{\mathrm{a}}$ & $2.84(1.14-7.12)$ & 1.00 & I.73 (0.73-4.06) & $0.84(0.21-3.38)$ \\
\hline Muscle Invasive BC (n) & 25 & 70 & 34 & 11 \\
\hline Model $2^{\mathrm{a}}$ & I.47 (0.7I-3.06) & 1.00 & $0.98(0.50-1.94)$ & $2.93(1.15-7.51)$ \\
\hline \multicolumn{5}{|l|}{ All-cause mortality } \\
\hline$B C(n)$ & 61 & 181 & 102 & 34 \\
\hline Model I & $1.29(0.86-1.94)$ & 1.00 & $\mathrm{I} .28(0.9 \mathrm{I}-\mathrm{I} .8 \mathrm{I})$ & $1.36(0.80-2.30)$ \\
\hline Model 2 & $1.36(0.90-2.07)$ & 1.00 & $1.37(0.96-1.93)$ & $\mathrm{I} .47(0.86-2.5 \mathrm{I})$ \\
\hline Non-Muscle Invasive BC (n) & 36 & 111 & 68 & 23 \\
\hline Model $2^{\mathrm{a}}$ & $1.97(1.06-3.65)$ & 1.00 & $1.52(0.91-2.56)$ & $1.09(0.5 \mathrm{I}-2.3 \mathrm{I})$ \\
\hline Muscle Invasive BC (n) & 25 & 70 & 34 & II \\
\hline Model $2^{\mathrm{a}}$ & $1.08(0.58-2.02)$ & 1.00 & $0.99(0.57-I .7 I)$ & $2.21(0.94-5.18)$ \\
\hline \multicolumn{5}{|l|}{ Cancer-free controls } \\
\hline \multicolumn{5}{|l|}{ All-cause mortality } \\
\hline Controls (n) & 68 & 143 & 115 & 52 \\
\hline Model I ${ }^{\mathrm{a}}$ & I.IO (0.64-I.89) & 1.00 & $1.37(0.87-2.13)$ & $\mathrm{I} .25(0.7 \mid-2.2 \mathrm{I})$ \\
\hline Model $2^{\mathrm{a}}$ & $0.99(0.54-1.81)$ & 1.00 & $1.36(0.84-2.21)$ & $1.16(0.65-2.06)$ \\
\hline
\end{tabular}

Notes: Model I: Adjusted for age at index-day, sex, year of blood draw, batch number, tumor invasiveness. Model 2: Adjusted for age at index-day, sex, year of blood draw, batch number, tumor invasiveness, smoking status, body mass index, physical activity, education. ${ }^{a}$ Not adjusted for tumor invasiveness.

contrast to our finding of a slightly elevated BC-specific mortality associated with $25(\mathrm{OH}) \mathrm{D}$ deficiency, they observed no association. However, compared to the present study, their study population was limited to male smokers only, and information on tumor stage was not included.

Our analysis indicated an increased risk of BC-specific mortality for $25(\mathrm{OH}) \mathrm{D}$ levels below $50 \mathrm{nmol} / \mathrm{L}$. In accordance with our finding, a large prospective cohort study from the United Kingdom reported increased cancerspecific mortality for $25(\mathrm{OH}) \mathrm{D}$ concentrations $\leq 45 \mathrm{nmol} /$ L, when studying all cancer sites combined. ${ }^{37}$ A German cohort study found increased risk of mortality for concentrations below $30 \mathrm{nmol} / \mathrm{L}$ when compared with higher concentrations. ${ }^{38}$ The $25(\mathrm{OH}) \mathrm{D}$ levels defined as critical to increase the risk of cancer mortality vary between studies, which is probably due to variations in laboratory methods, but also because of huge individual and environmental variations in $25(\mathrm{OH}) \mathrm{D}$ levels, including seasonal variation, which makes it difficult to define absolute critical levels of $25(\mathrm{OH}) \mathrm{D} .^{26}$

Our analysis revealed a non-linear relationship between 25(OH)D and $\mathrm{BC}$-specific mortality with the highest risk for low concentrations. In agreement with our findings, most studies report a non-linear relationship between 25 $(\mathrm{OH}) \mathrm{D}$ levels and cancer mortality, but with various 

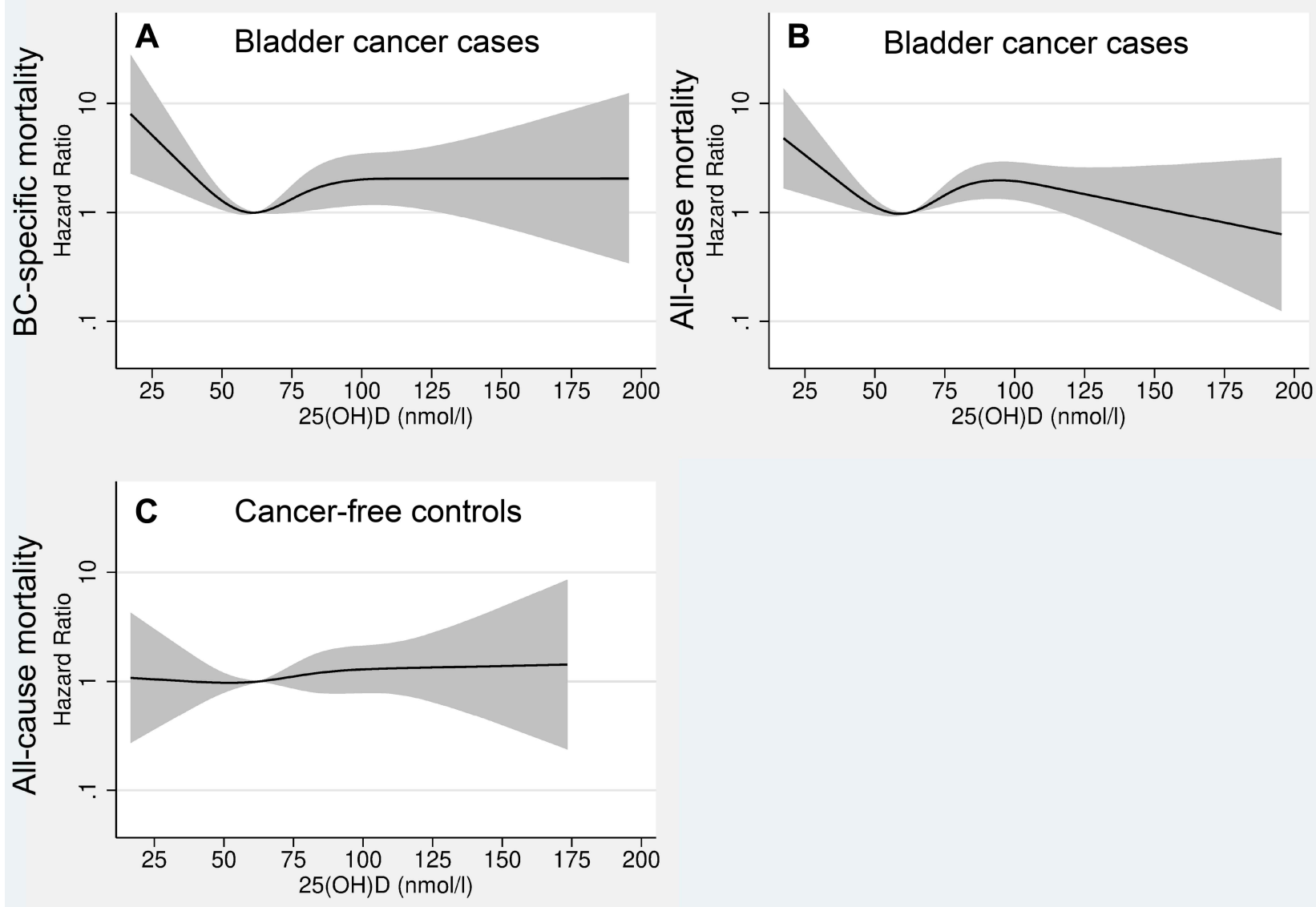

Figure 2 Restricted cubic splines displaying hazard ratios of bladder cancer (BC)-specific mortality(A) and all-cause mortality among BC cases (B), and all-cause mortality, among cancer-free controls (C), with $95 \%$ confidence intervals, according to 25 -hydroxyvitamin D levels. The reference was set to 62.5 nmol/L. All exposure risk curves were adjusted for age at index date, sex, year of blood draw, tumor invasiveness (expect cancer-free controls), batch number, smoking status, body mass index, physical activity and education (Model 2). The hazard ratio is presented on a logarithmic y-axis.

shapes, including increased mortality up to a certain value, but also a U- or a reversed J-shaped curve, where both low and high concentrations increase the risk of mortality have been reported. ${ }^{37-40}$

Analyses stratified by invasiveness showed that the association between 25(OH)D deficiency and BC-specific mortality was restricted to NMIBC. Thus, indicate that 25 $(\mathrm{OH}) \mathrm{D}$ levels does no longer provide a protective effect when the cancer becomes more invasive. This is in accordance with another study that observed an association between $25(\mathrm{OH}) \mathrm{D}$ levels and survival only in low stage non-small lung cancer and not in advanced non-small lung cancer. ${ }^{41,42} \mathrm{~A}$ likely reason for observing an association in the NMIBC group only might be the severity of the disease in MIBC patients. Thus, cancer inhibiting effects of vitamin $\mathrm{D}$ may have a lower probability to impact the outcome. Moreover, sufficient 25(OH)D concentrations are among other things suggested to protect against invasion and progression of the disease and might be more protective at lower stages, preventing further development of the disease. ${ }^{11}$ Another possible explanation of only observing an effect among NMIBC could be related to treatment, as individuals receive different treatment, dependent on tumor invasiveness. ${ }^{43}$ In addition to surgery, high-grade NMIBC is treated with intravesical Bacillus Calmette-Guerin (BCG) immunotherapy. ${ }^{43}$ Since vitamin $\mathrm{D}$ metabolites are known for its immunomodulating features, it is suggested that $25(\mathrm{OH}) \mathrm{D}$ is involved in mediating the response from BCG treatment. A study performed in mice showed that combining vitamin $\mathrm{D}$ supplement with BCG increased the response compared with BCG treatment alone. ${ }^{44}$ Thus, deficient 25(OH)D levels might influence the response to $\mathrm{BCG}$ treatment, which again leads to a lower mortality risk in NMIBC when compared 

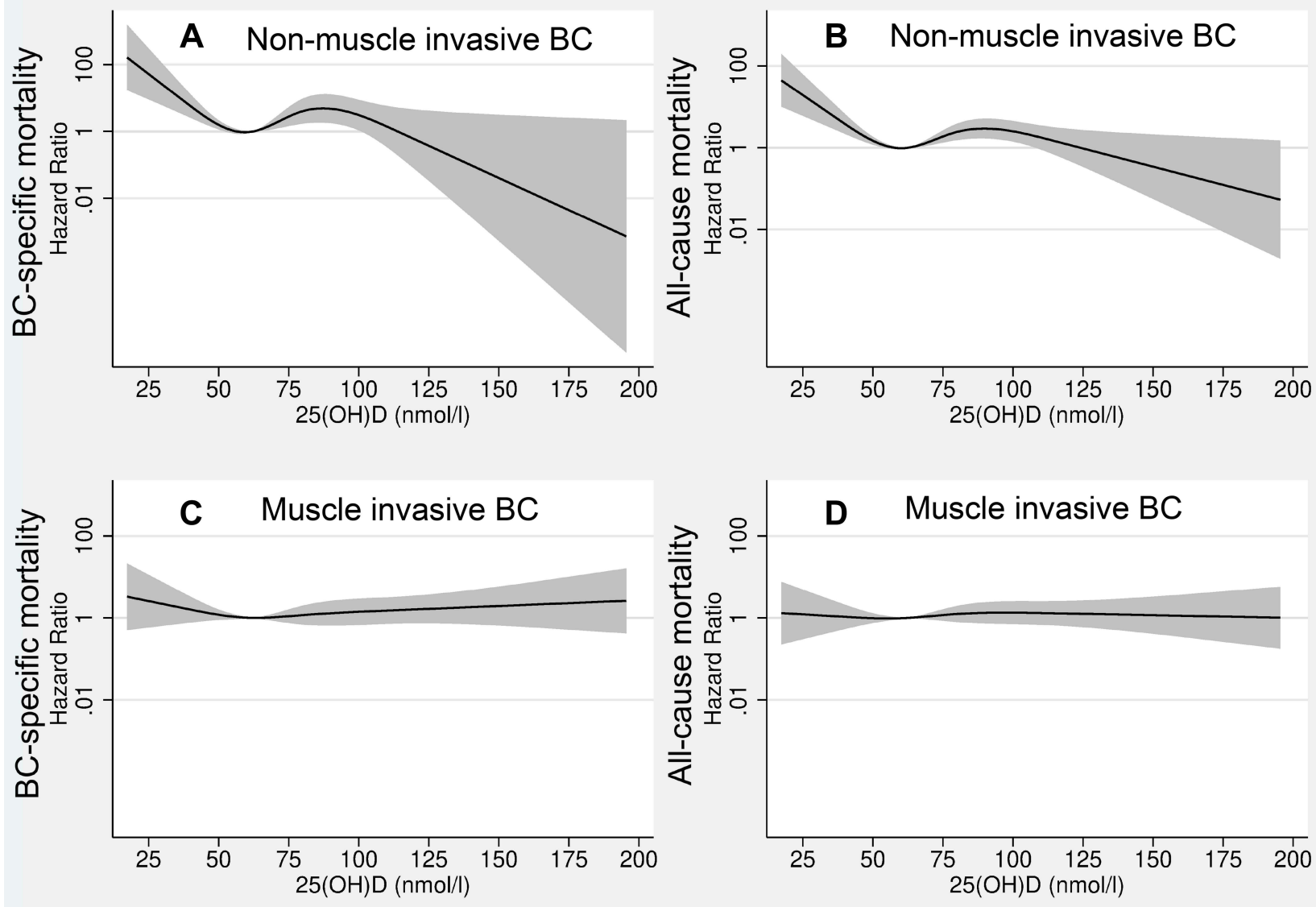

Figure 3 Restricted cubic splines displaying hazard ratios of bladder cancer (BC)-specific mortality (A) and all-cause mortality (B) among non-muscle invasive BC, and BCspecific mortality (C) and all-cause mortality (D) among muscle invasive BC, with $95 \%$ confidence intervals, according to 25 -hydroxyvitamin D levels. The reference was set to $62.5 \mathrm{nmol} / \mathrm{L}$. All exposure risk curves were adjusted for age at index date, sex, year of blood-draw, batch number, smoking status, body mass index, physical activity and education (Model 2). The hazard ratio is presented on a logarithmic $y$-axis.

to reference $25(\mathrm{OH}) \mathrm{D}$ levels. We also observed a tendency of increased BC-specific mortality for higher concentrations, which was solely visible in MIBC patients.

The 25(OH)D levels have also been inversely associated with cardiovascular mortality and all-cause mortality. ${ }^{15}$ In our analysis, $25(\mathrm{OH}) \mathrm{D}$ was primarily associated with BC-specific mortality, and a tendency of a similar trend was observed for all-cause mortality among BC cases. However, among cancer-free controls, we found no associations between all-cause mortality and 25(OH)D concentrations. Vitamin D deficiency is primarily caused by insufficient sun exposure, poor diet or obesity but are also associated with increasing age, and smoking history, which in turn could influence BC mortality. ${ }^{45}$ In the present study, such potential lifestylerelated confounding factors (smoking, physical activity and BMI) did not change the results materially. In addition, stratified analyses did not reveal any effect modification of any of the included lifestyle variables. However, potential residual and/or unmeasured confounding from diet, and other conditions/diseases might persist.

Our study has several strengths. We only used serum samples, for assessment of $25(\mathrm{OH}) \mathrm{D}$, collected at least 5 years prior to the primary cancer diagnosis, reducing the risk of $\mathrm{BC}$ to influence the 25(OH)D levels. Also, we adjusted for potential confounding lifestyle factors, including detailed information on smoking history. A major limitation of our study is that we only had a single and prediagnostic measurement of serum $25(\mathrm{OH}) \mathrm{D}$, which does not necessarily represent the individual's longitudinal vitamin D status relevant to cancer progression. Moreover, we do not have information about the intake of vitamin D supplements, which might have changed the $25(\mathrm{OH}) \mathrm{D}$ levels. However, former studies have shown that 
Table 3. Hazard Ratio (HR) and 95\% Confidence Interval (Cl) of Bladder Cancer-Specific Mortality by Season-Adjusted 25Hydroxyvitamin D Levels, Stratified by Smoking Status, Body Mass Index (BMI) and Physical Activity

\begin{tabular}{|c|c|c|c|c|c|c|c|c|c|}
\hline & \multicolumn{9}{|c|}{ 25-Hydroxyvitamin D } \\
\hline & \multirow{2}{*}{\multicolumn{2}{|c|}{$\begin{array}{l}\text { Deficient } \\
<50 \mathrm{nmol} / \mathrm{L}\end{array}$}} & \multirow{2}{*}{\multicolumn{2}{|c|}{$\begin{array}{l}\text { Insufficient } \\
\text { 50-74 nmol/L }\end{array}$}} & \multirow{2}{*}{\multicolumn{2}{|c|}{$\begin{array}{l}\text { Optimal } \\
75-99 \mathrm{nmol} / \mathrm{L}\end{array}$}} & \multirow{2}{*}{\multicolumn{2}{|c|}{$\begin{array}{l}\text { High Optimal } \\
\geq 100 \mathrm{nmol} / \mathrm{L}\end{array}$}} & \multirow[t]{3}{*}{ p Interaction } \\
\hline & & & & & & & & & \\
\hline & $\mathbf{n}$ & HR (95\% Cl) & $\mathbf{n}$ & HR (95\% Cl) & $\mathbf{n}$ & HR (95\% Cl) & $\mathbf{n}$ & HR (95\% Cl) & \\
\hline \multicolumn{10}{|l|}{ Smoking status ${ }^{\mathrm{a}}$} \\
\hline Never smoker & 8 & $5.89(0.77-44.9)$ & 38 & 1.00 & 20 & $0.21(0.02-2.75)$ & 8 & $0.31(0.026-3.84)$ & \\
\hline Former smoker & 9 & $5.03(0.94-26.9)$ & 39 & 1.00 & 25 & $2.49(0.72-8.6 \mathrm{I})$ & 7 & $1.72(0.27-10.9)$ & \\
\hline Current smoker & 44 & $1.65(0.84-3.23)$ & 104 & 1.00 & 57 & $1.32(0.66-2.66)$ & 19 & $1.61(0.54-4.76)$ & 0.846 \\
\hline \multicolumn{10}{|l|}{$\mathrm{BMI}$} \\
\hline$<25 \mathrm{~kg} / \mathrm{m}^{2}$ & 31 & $1.92(0.90-4.11)$ & 97 & 1.00 & 60 & $1.63(0.83-3.19)$ & 20 & $1.56(0.53-4.56)$ & \\
\hline$\geq 25 \mathrm{~kg} / \mathrm{m}^{2}$ & 30 & $1.97(0.82-4.77)$ & 84 & 1.00 & 42 & $1.08(0.45-2.60)$ & 14 & $2.16(0.64-7.28)$ & 0.888 \\
\hline \multicolumn{10}{|l|}{ Physical activity ${ }^{c}$} \\
\hline Sedentary & 21 & $0.84(0.14-4.85)$ & 36 & 1.00 & 17 & $0.18(0.017-2.00)$ & 4 & $0.30(0.017-5.45)$ & \\
\hline Active & 40 & $1.88(0.98-3.62)$ & 145 & 1.00 & 85 & $1.33(0.78-2.27)$ & 30 & $1.91(0.84-4.35)$ & 0.788 \\
\hline
\end{tabular}

Notes: adjusted for age at index-day, sex, year of blood draw, batch number, tumor invasiveness, body mass index, physical activity, education. ${ }^{b}$ Adjusted for age at indexday, sex, year of blood draw, batch number, tumor invasiveness, smoking status, physical activity, education. 'Adjusted for age at index-day, sex, year of blood draw, batch number, tumor invasiveness, body mass index, smoking status, education.

circulating $25(\mathrm{OH}) \mathrm{D}$ measured several years apart were well correlated. ${ }^{46,47}$ It is also a weakness that we did not have information about treatment and other comorbidities, which is of importance when evaluating cancer-specific mortality. However, treatment of $\mathrm{BC}$ is standardized in Norway, according to invasiveness and has been relatively unchanged over the last decades. ${ }^{48}$

\section{Conclusion}

$25(\mathrm{OH}) \mathrm{D}$ deficiency $(<50 \mathrm{nmol} / \mathrm{L})$ at least 5 years prior to a $\mathrm{BC}$ diagnosis was associated with increased risk of $\mathrm{BC}$ specific mortality, when compared to insufficient levels (50-74 nmol/L). The results were only evident among NMIBC patients, suggesting a more critical role of vitamin $\mathrm{D}$ in an early stage of the disease.

\section{Abbreviations}

25(OH)D, 25-hydroxyvitamin $\mathrm{D} ; \quad 1,25 \mathrm{OH}_{2} \mathrm{D}, \quad 1-25-$ dihydroxyvitamin $\mathrm{D}$; BC, urothelial bladder cancer; BMI, body mass index; CRN, Cancer Registry of Norway; HR, hazard ratio; $\mathrm{CI}$, confidence interval; SD, standard deviation.

\section{Data Sharing Statement}

The data are available as presented in the paper. According to Norwegian legislation, our approvals to use the data for the current study do not allow us to distribute or make the data directly available to other parties. Any requests to share these data will be subject to formal approval from each data source used in this project and to the General Data Protection Regulation. Requests for data sharing/case pooling may be directed to the corresponding author.

\section{Ethics Approval and Informed Consent}

The study is approved by the Regional Committee for Medical and Health Research Ethics. The study is also approved by the CRN and the Janus Serum Bank Board. All data management and analyses were conducted according to current legislation and regulation of privacy, without any possibilities for individual identification.

\section{Acknowledgments}

We thank all individuals that participated in the Norwegian Regional Health Studies and donated blood to the Janus Serum Bank of Norway. We also thank the Norwegian Cancer Society for providing funding for this study.

\section{Author Contributions}

All authors contributed to study design, data analysis, drafting or revising the article, gave final approval of the version to be published, and agreed to be accountable for 
all aspects of the work. Trude E Robsahm and Bettina K Andreassen shared last authorship.

\section{Funding}

The study is funded by the Norwegian Cancer Society.

\section{Disclosure}

Dr Jo S Stenehjem reports grants from Research Council of Norway, outside the submitted work. The authors report no conflicts of interest in this work.

\section{References}

1. Bray F, Ferlay J, Soerjomataram I, Siegel RL, Torre LA, Jemal A. Global cancer statistics 2018: GLOBOCAN estimates of incidence and mortality worldwide for 36 cancers in 185 countries. CA Cancer J Clin. 2018;68(6):394-424. doi:10.3322/caac.21492

2. Kucuk U, Pala EE, Cakır E, et al. Clinical, demographic and histopathological prognostic factors for urothelial carcinoma of the bladder. Cent Eur J Urol. 2015;68(1):30-36. doi:10.5173/ ceju.2015.01.465

3. Hou L, Hong X, Dai M, et al. Association of smoking status with prognosis in bladder cancer: a meta-analysis. Oncotarget. 2017;8 (1):1278-1289. doi:10.18632/oncotarget.13606

4. Kluth LA, Xylinas E, Crivelli JJ, et al. Obesity is associated with worse outcomes in patients with T1 high grade urothelial carcinoma of the bladder. $J$ Urol. 2013;190(2):480-486. doi:10.1016/j. juro.2013.01.089

5. Theodoratou E, Tzoulaki I, Zgaga L, Ioannidis JPA. Vitamin D and multiple health outcomes: umbrella review of systematic reviews and meta-analyses of observational studies and randomised trials. $B M J$. 2014;348:g2035. doi:10.1136/bmj.g2035

6. Sluyter JD, Manson JE, Scragg R. Vitamin D and clinical cancer outcomes: a review of meta-analyses. JBMR Plus. 2021;5:e10420. doi:10.1002/jbm4.10420

7. Keum N, Lee DH, Greenwood DC, Manson JE, Giovannucci E. Vitamin D supplementation and total cancer incidence and mortality: a meta-analysis of randomized controlled trials. Ann Oncol. 2019;30 (5):733-743. doi:10.1093/annonc/mdz059

8. Nair R, Maseeh A. Vitamin D: the "sunshine" vitamin. J Pharmacol Pharmacother. 2012;3(2):118-126.

9. Bikle DD. Vitamin D metabolism, mechanism of action, and clinical applications. Chem Biol. 2014;21(3):319-329. doi:10.1016/j. chembiol.2013.12.016

10. Bikle D. Nonclassic actions of vitamin D. J Clin Endocrinol Metab. 2009;94(1):26-34. doi:10.1210/jc.2008-1454

11. Vanoirbeek E, Krishnan A, Eelen G, et al. The anti-cancer and antiinflammatory actions of $1,25(\mathrm{OH})_{2} \mathrm{D}_{3}$. Best Pract Res Clin Endocrinol Metab. 2011;25(4):593-604. doi:10.1016/j.beem.20 11.05 .001

12. Zhang Y, Fang F, Tang J, et al. Association between vitamin D supplementation and mortality: systematic review and meta-analysis. BMJ. 2019;366:14673. doi:10.1136/bmj.14673

13. Chandler PD, Chen WY, Ajala ON, et al. Effect of vitamin D3 supplements on development of advanced cancer: a secondary analysis of the VITAL randomized clinical trial. JAMA Netw Open. 2020;3(11): e2025850-e2025850. doi:10.1001/jamanetworkopen.2020.25850

14. Schöttker B, Jorde R, Peasey A, et al. Vitamin D and mortality: meta-analysis of individual participant data from a large consortium of cohort studies from Europe and the United States. BMJ. 2014;348: g3656. doi:10.1136/bmj.g3656
15. Chowdhury R, Kunutsor S, Vitezova A, et al. Vitamin D and risk of cause specific death: systematic review and meta-analysis of observational cohort and randomised intervention studies. BMJ. 2014;348: g1903. doi:10.1136/bmj.g1903

16. Yin L, Ordóñez-Mena JM, Chen T, Schöttker B, Arndt V, Brenner H. Circulating 25-hydroxyvitamin D serum concentration and total cancer incidence and mortality: a systematic review and meta-analysis. Prev Med. 2013;57(6):753-764. doi:10.1016/j.ypmed.2013.08.026

17. Afzal S, Brøndum-Jacobsen P, Bojesen SE, Nordestgaard BG. Genetically low vitamin D concentrations and increased mortality: Mendelian randomisation analysis in three large cohorts. $B M J$. 2014;349:g6330. doi:10.1136/bmj.g6330

18. Han J, Guo X, Yu X, et al. 25-hydroxyvitamin D and total cancer incidence and mortality: a meta-analysis of prospective cohort studies. Nutrients. 2019;11(10):2295. doi:10.3390/nu11102295

19. Vaughan-Shaw PG, O'Sullivan F, Farrington SM, et al. The impact of vitamin D pathway genetic variation and circulating 25-hydroxyvitamin D on cancer outcome: systematic review and meta-analysis. Br J Cancer. 2017;116(8):1092-1110. doi:10.1038/ bjc. 2017.44

20. Tretli S, Hernes E, Berg JP, Hestvik UE, Robsahm TE. Association between serum 25(OH)D and death from prostate cancer. $\mathrm{Br}$ J Cancer. 2009;100(3):450-454. doi:10.1038/sj.bjc.6604865

21. Robsahm TE, Tretli S, Torjesen PA, Babigumira R, Schwartz GG. Serum 25-hydroxyvitamin D levels predict cancer survival: a prospective cohort with measurements prior to and at the time of cancer diagnosis. Clin Epidemiol. 2019;11:695-705. doi:10.2147/ CLEP.S207230

22. Mondul AM, Weinstein SJ, Layne TM, Albanes D. Vitamin D and cancer risk and mortality: state of the science, gaps, and challenges. Epidemiol Rev. 2017;39(1):28-48. doi:10.1093/epirev/mxx005

23. Weinstein SJ, Mondul AM, Yu K, et al. Circulating 25-hydroxyvitamin $\mathrm{D}$ up to 3 decades prior to diagnosis in relation to overall and organ-specific cancer survival. Eur J Epidemiol. 2018;33(11):1087-1099. doi:10.1007/s10654-018-0428-2

24. Ben Fradj MK, Bibi M, Hammami MB, Kallel A, Nouira Y, Feki M. Low plasma 25-hydoxyvitamin $\mathrm{D}$ at diagnosis predicts poor outcomes in patients with bladder cancer: a prospective cohort study. Nutr Cancer. 2021;73(1):55-61. doi:10.1080/01635581.2 020.1737150

25. Peiris AN, Bailey BA, Manning T. Relationship of vitamin D monitoring and status to bladder cancer survival in veterans. South Med J. 2013;106(2):126-130. doi:10.1097/SMJ.0b013 e3182824d00

26. Ferrari D, Lombardi G, Banfi G. Concerning the vitamin D reference range: pre-analytical and analytical variability of vitamin D measurement. Biochem Med (Zagreb). 2017;27(3):030501. doi:10.11613/BM.2017.030501

27. Robsahm TE, Schwartz GG, Tretli S. The inverse relationship between 25-hydroxyvitamin D and cancer survival: discussion of causation. Cancers (Basel). 2013;5(4):1439-1455. doi:10.3390/ cancers 5041439

28. Langseth H, Gislefoss RE, Martinsen JI, Dillner J, Ursin G. Cohort profile: the Janus Serum bank cohort in Norway. Int $J$ Epidemiol. 2017;46(2):403-404g.

29. Hjerkind KV, Gislefoss RE, Tretli S, et al. Cohort profile update: the Janus Serum bank cohort in Norway. Int J Epidemiol. 2017;46 (4):1101-1102f.

30. Hektoen HH, Robsahm TE, Stenehjem JS, et al. Vitamin D and vitamin D-binding protein and risk of bladder cancer: a nested case-control study in the Norwegian Janus Serum Bank Cohort. Cancer Med. 2021;10(12):4107-4116. doi:10.1002/cam4.3960

31. Larsen IK, Smastuen M, Johannesen TB, et al. Data quality at the Cancer Registry of Norway: an overview of comparability, completeness, validity and timeliness. Eur J Cancer. 2009;45(7):1218-1231. doi:10.1016/j.ejca.2008.10.037 
32. Holick MF. Vitamin D status: measurement, interpretation, and clinical application. Ann Epidemiol. 2009;19(2):73-78. doi:10.1016/j. annepidem.2007.12.001

33. Lips P, Cashman KD, Lamberg-Allardt C, et al. Current vitamin D status in European and Middle East countries and strategies to prevent vitamin D deficiency: a position statement of the European Calcified Tissue Society. Eur J Endocrinol. 2019;180(4):P23-P54.

34. Harrell FE. General aspects of fitting regression models. In: Regression Modeling Strategies: With Applications to Linear Models, Logistic and Ordinal Regression, and Survival Analysis. Cham: Springer International Publishing; 2015:13-44.

35. Grant WB, Garland CF. The association of solar ultraviolet B (UVB) with reducing risk of cancer: multifactorial ecologic analysis of geographic variation in age-adjusted cancer mortality rates. Anticancer Res. 2006;26(4A):2687-2699.

36. Boscoe FP, Schymura MJ. Solar ultraviolet-B exposure and cancer incidence and mortality in the United States, 1993-2002. BMC Cancer. 2006;6(1):264. doi:10.1186/1471-2407-6-264

37. Fan X, Wang J, Song M, et al. Vitamin D status and risk of all-cause and cause-specific mortality in a large cohort: results from the UK biobank. J Clin Endocrinol Metab. 2020;105(10):e3606-e3619. doi:10.1210/clinem/dgaa432

38. Schottker B, Haug U, Schomburg L, et al. Strong associations of 25-hydroxyvitamin D concentrations with all-cause, cardiovascular, cancer, and respiratory disease mortality in a large cohort study. Am J Clin Nutr. 2013;97(4):782-793. doi:10.3945/ajcn.112.047712

39. Durup D, Jørgensen HL, Christensen J, Schwarz P, Heegaard AM, Lind B. A reverse J-shaped association of all-cause mortality with serum 25-hydroxyvitamin D in general practice: the CopD study. J Clin Endocrinol Metab. 2012;97(8):2644-2652. doi:10.1210/ jc.2012-1176

40. Grant WB, Karras SN, Bischoff-Ferrari HA, et al. Do studies reporting ' $U$ '-shaped serum 25-hydroxyvitamin D-health outcome relationships reflect adverse effects? Dermatoendocrinol. 2016;8(1): e1187349. doi:10.1080/19381980.2016.1187349
41. Heist RS, Zhou W, Wang Z, et al. Circulating 25-hydroxyvitamin D, VDR polymorphisms, and survival in advanced non-small-cell lung cancer. J Clin Oncol. 2008;26(34):5596-5602. doi:10.1200/JCO.2008.18.0406

42. Zhou W, Heist RS, Liu G, et al. Circulating 25-hydroxyvitamin D levels predict survival in early-stage non-small-cell lung cancer patients. J Clin Oncol. 2007;25(5):479-485. doi:10.1200/JCO.2006.07.5358

43. American Society of Clinical Oncology.Bladder cancer: treatments by stage; 2021. Available from: https:/www.cancer.net/ cancer-types/bladder-cancer/treatments-stage. Accessed August 30, 2021.

44. Hsu J-W, Yin P-N, Wood R, Messing J, Messing E, Lee Y-F. 1 alpha, 25-dihydroxylvitamin D3 promotes Bacillus Calmette-Guérin immunotherapy of bladder cancer. Oncotarget. 2013;4(12):2397-2406. doi:10.18632/oncotarget.1494

45. Lips P, van Schoor NM, de Jongh RT. Diet, sun, and lifestyle as determinants of vitamin D status. Ann N Y Acad Sci. 2014;1317 (1):92-98. doi:10.1111/nyas.12443

46. Hofmann JN, Yu K, Horst RL, Hayes RB, Purdue MP. Long-term variation in serum 25-hydroxyvitamin $\mathrm{D}$ concentration among participants in the prostate, lung, colorectal, and ovarian cancer screening trial. Cancer Epidemiol Biomarkers Prev. 2010;19(4):927-931. doi:10.1158/1055-9965.EPI-09-1121

47. Haddad JG. Plasma vitamin D-binding protein (Gc-globulin): multiple tasks. J Steroid Biochem Mol Biol. 1995;53(1-6):579-582. doi:10.1016/0960-0760(95)00104-8

48. Helsebiblioteket.National guidelines bladder cancer treatment; 2021. Available from: https://www.helsebiblioteket.no/retningslinjer/bl\% C3\%A6rekreft/utgivelsesinformasjon. Accessed August 30, 2021.
Clinical Epidemiology

\section{Publish your work in this journal}

Clinical Epidemiology is an international, peer-reviewed, open access, online journal focusing on disease and drug epidemiology, identification of risk factors and screening procedures to develop optimal preventative initiatives and programs. Specific topics include: diagnosis, prognosis, treatment, screening, prevention, risk factor modification,

Submit your manuscript here: https://www.dovepress.com/clinical-epidemiology-journal

\section{Dovepress}

systematic reviews, risk \& safety of medical interventions, epidemiology \& biostatistical methods, and evaluation of guidelines, translational medicine, health policies \& economic evaluations. The manuscript management system is completely online and includes a very quick and fair peer-review system, which is all easy to use. 